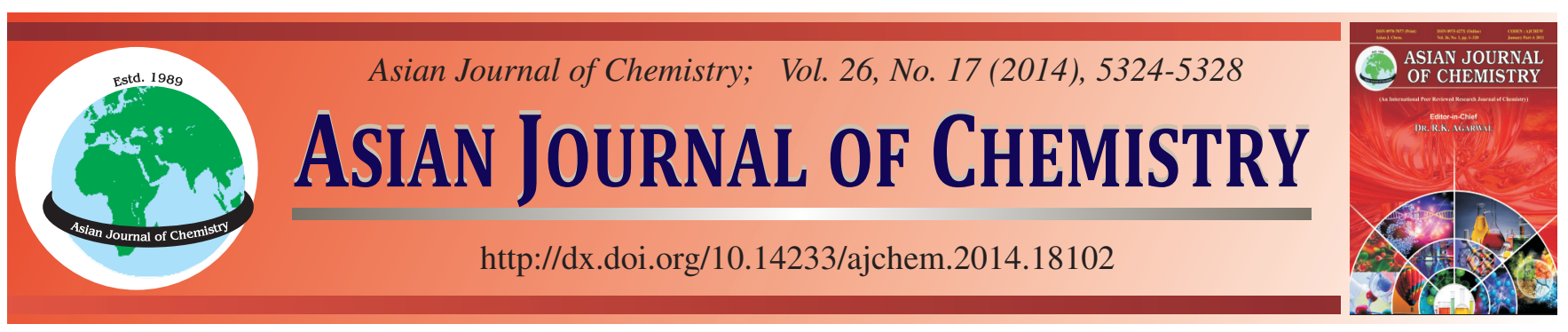

\title{
Removal of Volatile Organic Compounds Using Biofilter $\dagger$
}

\author{
YANG Lv ${ }^{1, *}$, Chenguang LiU ${ }^{2}$, ZhenPING Qu ${ }^{3}$ and Jia Wei ${ }^{4}$
}

${ }^{1}$ School of Civil Engineering, Dalian University of Technology, Dalian 116000, P.R. China

${ }^{2}$ School of Life Science and Biotechnology, Dalian University of Technology, Dalian 116000, P.R. China

${ }^{3}$ School of Environmental Science and Technology, Dalian University of Technology, Dalian 116000, P.R. China

${ }^{4}$ Dalian Environmental Monitoring Centre, No. 58 Lianshan Road, Shahekou District, Dalian 116000, P.R. China

*Corresponding author: Fax: +86 411 84706371; Tel: +86 411 84707684; E-mail: lvyang@ dlut.edu.cn

\begin{abstract}
In this study, volatile organic compounds (VOCs) was removed using biofilter coupled with bake-out exhaust. The removal efficiencies under different temperatures and the pollutant concentrations in the airstream were analyzed. It can be found that removal effect under $30^{\circ} \mathrm{C}$ is better than of $40^{\circ} \mathrm{C}$ in biotrickling filter. In addition, with physiological and biochemical experiments as wells as $16 \mathrm{~S}$ rDNA and bacterial fatty acids, four bacterial strains were isolated from the biotrickling filter and identified. At last, these bacterial strains were characterized as Pseudomonas sp., Kocuria sp., Arthrobacter sp. and Bacillus sp. Based on the adsorption-biofilm purification model, the dynamic course of biotechnology for the low concentrations of volatile organic compounds was simulated. The results indicate that the model predicted value and the actual value correlates greatly.
\end{abstract}

Keywords: Formaldehyde, Volatile organic compounds, Biofilter, Remove.

\section{INTRODUCTION}

With the rapid development of economy in China, indoor decoration and reform using synthetic building materials have become more and more common. However, all this lead to lots of indoor air pollution problems which have been alluring human being's attention. Since the first indoor air quality and climate international conference opened in 1974, studies about effective indoor pollution management method have attracted more attention.

In waster management, biotechnology is regarded as a fairly new method for the application of bioprocess engineering. The application of biotechnology for the treatment of volatile organic compounds was first reported in the United States. Since the late 1980s, researchers from Germany and the Netherlands had used this biotechnology for controlling volatile organic compounds pollution successfully ${ }^{1}$. Additionally, in the last two decades, much research on biological treatment has been carried out in order to develop an important alternative to many physical and chemical techniques for the treatment of volatile organic compounds $\mathrm{s}^{2-4}$. The advantages of this technology over the above-mentioned air-cleaning methods include that (1) the by-products of biodegradation are innocuous and (2) biological processes are readily accepted as an environmentally friendly process. However, typical biotechnology has frequently been used for industrial pollutants removal and there has been no report of this method to treat indoor volatile organic compounds.

The main objective of this study is to investigate the treatability of volatile organic compounds using biofilter with the combination of bake-out exhaust. The effect of air stream temperature and volatile organic compounds concentrations on the biofilter performance was studied, and the high-efficient bacteria were isolated and identified.

\section{EXPERIMENTAL}

Firstly, active sludge was cultivated and made it contact with the packing in the biofilter to support the biofilm. Then through dynamic method artificially compounded the low concentration mixed organic air (formaldehyde, benzene, toluene, xylene), caused it adverse current to domesticate the biofilm through the biofilter. After the biofilm cultivation stable, connected the biofilter and the simulation box in the room. Then measure pollutant purification efficiency under different temperature and inlet air concentration, to study the effect and dynamic analysis of biological processing for indoor noxious air. 
Experiment setup: At first, baked out the building material to accelerate pollutant volatilization. Then, exhaust the toxic air into biological treatment setting by a pump. After that, purified air can be exhaust outside.

In this study, one test chamber (Fig. 1) was used to be representative of a newly renovated house. The biological treatment installment is one biofilter with the inside diameter $9 \mathrm{~cm}$ and height $100 \mathrm{~cm}$. The trickling-filter was loaded with the filter media. In this study, pottery piece was chosen as the packing material. The nourishing cream flowed down biofilter from the filtrate water tank in certain speed of flow, provided the nutrients for microorganism in the trickling filter. There is one connecting in the lower part of the trickling filter, the nourishing cream flowed out would enter the stock solution barrel, where the circulating pump was set. In fixed time, the nourishing cream would be back the filtrate water tank.

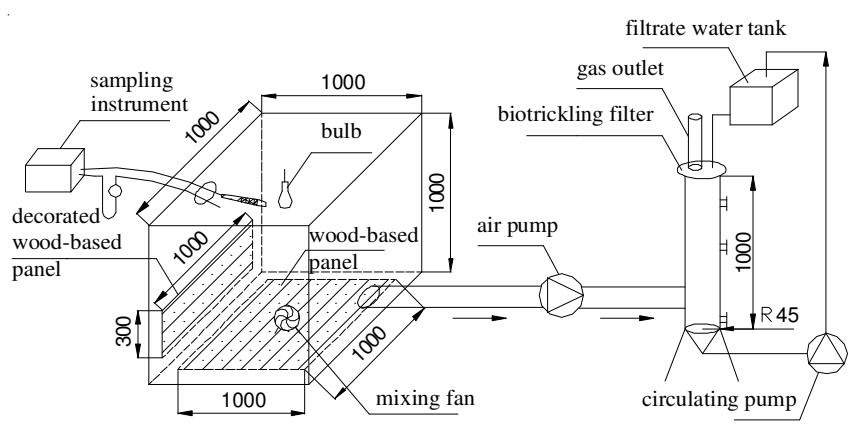

Fig. 1. Schematics of the experiment

In order to provide a suitable environment to sustain the microorganisms responsible for the biofiltration process, moisture content of the packing material ranged in $40-60 \%, \mathrm{pH}$ value was maintained at 6-7.

This experiment combined bake out exhaust and the biological treatment situation to determine biological treatment stage operation parameter. According to air exchange rate influence on volatile organic compounds removal, the research indicated removal quantity would be higher for higher air change rate. But constantly increase air exchange rate will lead to both energy waste and influence on gas resident time through the biological treatment installment. According to preliminary experiments, the flow rate of air stream was determined at $600 \mathrm{~L} / \mathrm{h}$, while the liquid flow at $20 \mathrm{~L} / \mathrm{h}$. This accord with the best gas flow, the liquid flow and the best ratio of fluid to air, which was demonstrated 0.03-0.1 in correlation experiment study ${ }^{5}$.

Effect of temperature: Temperature is an important ecological factor for bioremediation. In this study, considering bake-out before biological treatment, temperature was controlled at 30 and $40^{\circ} \mathrm{C}$, respectively. Purification efficiency of indoor decoration noxious air by the biofilter processing under 30 and $40{ }^{\circ} \mathrm{C}$ can be seen in Figs. 2 and 3 .

It can be seen that the removal efficiency of benzene is $65-70 \%$ when bake-out temperature is $30^{\circ} \mathrm{C}$, while the removal efficiencies of toluene and xylene are about 93 and $85 \%$, respectively. But when temperature raise to $40^{\circ} \mathrm{C}$, the removal efficiency of benzene maintains at 48.9-73\%, while the removal efficiencies of toluene and xylene maintains at 66.275 and 66.3-84 \%, respectively. Removal efficiencies under

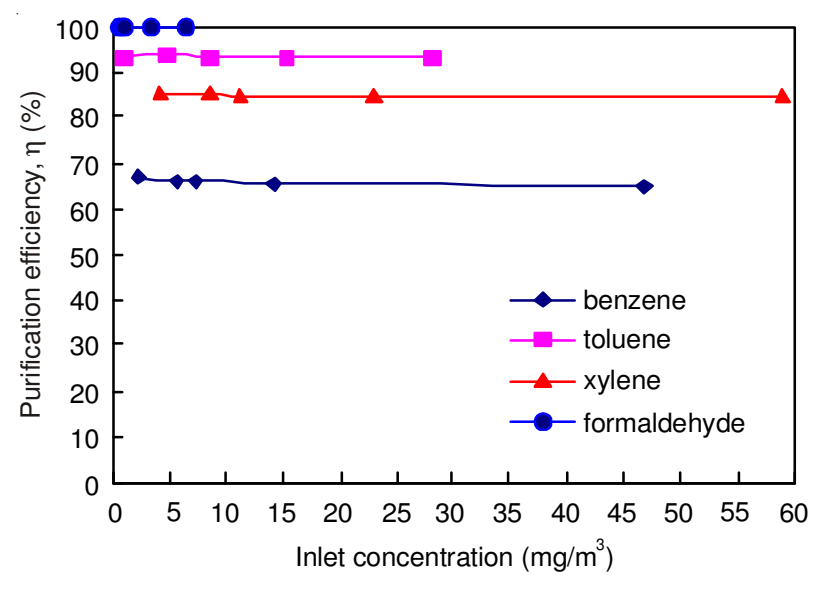

Fig. 2. Removal efficiencies at $30^{\circ} \mathrm{C}$

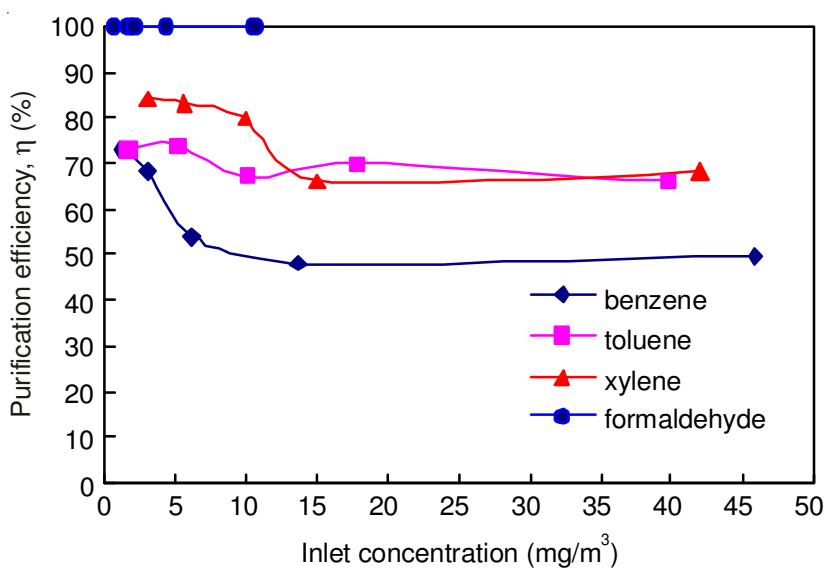

Fig. 3. Removal efficiencies at $40{ }^{\circ} \mathrm{C}$

$30{ }^{\circ} \mathrm{C}$ are higher than those under $40{ }^{\circ} \mathrm{C}$. The main reason is that, the pseudomonad is the superiority bacteria in biofilter, its growth temperature range is $4-43{ }^{\circ} \mathrm{C}$ and the most suitable temperature for bioremediation is about $30^{\circ} \mathrm{C}^{6}$.

Effect of volatile organic compound concentration in the air stream: In this study, the highest concentrations of formaldehyde, benzene, toluene and xylene in the air stream were $6.578,46.733,28.254$ and $59.008 \mathrm{mg} / \mathrm{m}^{3}$, respectively under $30^{\circ} \mathrm{C}$. The relationship between removal efficiencies and volatile organic compound concentrations in the air stream is shown in Fig. 4.

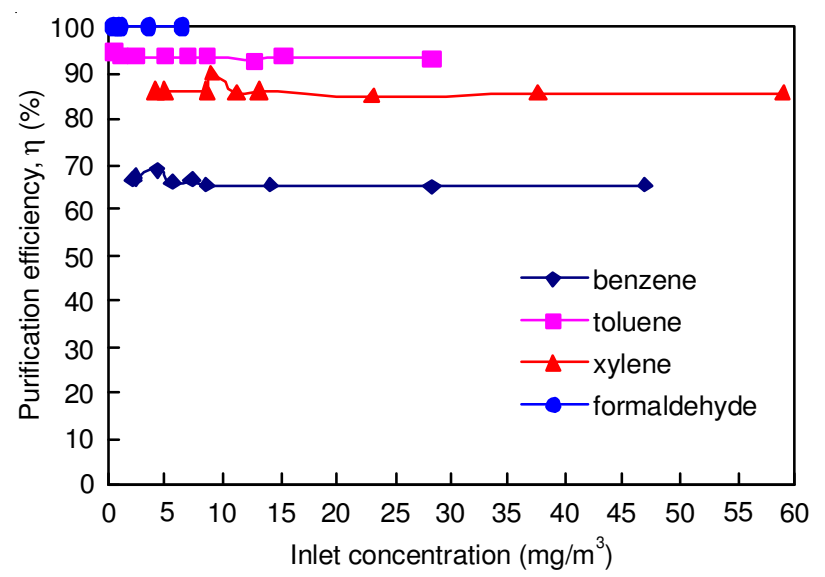

Fig. 4. Relationship between removal efficiencies and volatile organic compounds concentrations in the air stream 
It can be seen that removal efficiencies range in 65-70, 93 and 85-90\% when the concentrations of benzene, toluene and xylene in the air stream vary in the range of 2.254-46.733, $0.51-28.254$ and $4.166-59.008 \mathrm{mg} / \mathrm{m}^{3}$, respectively. On the other hand, formaldehyde can be completely removed when its concentration in the air stream is lower than $6.578 \mathrm{mg} / \mathrm{m}^{3}$. The main reason lies in that the formaldehyde is easily soluble, especially easy to dissolve in the water under the normal temperature and its highest watery solution concentration reaches to $55 \%$. Formaldehyde released from indoor decoration is not only decomposed by microbial degradation, but also absorbed by liquid which is sprayed by the biofilter.

Isolation and identification of bacteria: In this study, $10 \mathrm{~g}$ padding was taken from the biotrickling filter. The padding was diluted by $90 \mathrm{~mL}$ sterilized water in $250 \mathrm{~mL}$ Erlenmeyer flask with shaking at $120 \mathrm{rpm}$ for $20 \mathrm{~min}$. The $0.1 \mathrm{~mL}$ dilution was taken from the Erlenmeyer flask after diluted to 10-6 and spread on basal medium plates (agar $18 \mathrm{~g}$, peptone $10 \mathrm{~g}$, beef broth $5 \mathrm{~g}, \mathrm{NaCl} 5 \mathrm{~g}$, distilled water $1,000 \mathrm{~mL}, \mathrm{pH}$ 7) to culture in an incubator. When colonies grew during incubation and became visible on the basal medium plates, bacteria were transferred from basal medium to selective medium (Agar $18 \mathrm{~g}$, $\mathrm{MgCl}_{2} \cdot 6 \mathrm{H}_{2} \mathrm{O} 3.34 \mathrm{~g}, \mathrm{NH}_{4} \mathrm{Cl} 2 \mathrm{~g}, \mathrm{NaH}_{2} \mathrm{PO}_{4} 1 \mathrm{~g}, \mathrm{FeSO}_{4} \cdot 7 \mathrm{H}_{2} \mathrm{O}$ $0.012 \mathrm{~g}, \mathrm{MnSO}_{4} \cdot 7 \mathrm{H}_{2} \mathrm{O} 0.003 \mathrm{~g}, \mathrm{ZnSO}_{4} \cdot 7 \mathrm{H}_{2} \mathrm{O} 0.003 \mathrm{~g}$, $\mathrm{CoSO}_{4} \cdot 7 \mathrm{H}_{2} \mathrm{O} 0.001 \mathrm{~g}$, distilled water $1,000 \mathrm{~mL}, \mathrm{pH}$ 7) with one of formaldehyde, benzene, toluene or xylene. Because the pollutant was the sole carbon source of the selective medium, the bacteria which would grow on the selective medium would biodegrade the pollutant. Colonies were categorized based on colour and shape. The bacteria was obtained by picking single colonies and transferred to the enriched medium $(\mathrm{NaCl} 5 \mathrm{~g}$, $\mathrm{MgCl}_{2} \cdot 6 \mathrm{H}_{2} \mathrm{O} 3.34 \mathrm{~g}, \mathrm{KH}_{2} \mathrm{PO}_{4} 1 \mathrm{~g},\left(\mathrm{NH}_{4}\right)_{2} \mathrm{SO}_{4} 1 \mathrm{~g}, \mathrm{FeSO}_{4} \cdot 7 \mathrm{H}_{2} \mathrm{O}$ $0.012 \mathrm{~g}, \mathrm{MnSO}_{4} \cdot 7 \mathrm{H}_{2} \mathrm{O} 0.003 \mathrm{~g}, \mathrm{ZnSO}_{4} \cdot 7 \mathrm{H}_{2} \mathrm{O} 0.003 \mathrm{~g}$, $\mathrm{CoSO}_{4} \cdot 7 \mathrm{H}_{2} \mathrm{O} 0.001 \mathrm{~g}$, distilled water $\left.1,000 \mathrm{~mL}, \mathrm{pH} 7\right)$. The bacteria which would make a maximum reduction of the pollutant concentration in the enriched medium plates would be the best strain. In this study, the formaldehyde degradation strain was named as L1. For benzene, toluene and xylene, strains were named as L2, L3 and L4, respectively.

\section{Methods for isolation and identification of bacteria}

High effective strains were identified according to the following three methods: Physiological and biochemical experiments: L1, L2, L3 and L4 were isolated and identified by the physiological and biochemical experimental methods, which are (1) oxidase test; (2) catalase test; (3) glucide ferment and oxidation; (4) hydrolysis of starch; (5) methyl red test; (6) Voges-proskauer test; (7) nitrate deoxidize test.

Identification of bacteria by gas-chromatography of cellular fatty acids: Previous studies have demonstrated that cellular fatty acid analysis is a useful tool for identifying unknown strains ${ }^{8}$. Each isolated bacterium was inoculated on the plate medium with four quadrant separate parts. For the optimum analysis of the concentration, bacterial cells were taken from the third quadrant among four quadrant separate parts of the plate after their growth and they were identified by gas-chromatography.
Molecular analysis: The 16S rDNA genes of L1, L2, L3 and L4 were isolated and amplified by polymerase chain reaction (PCR) using primers of bacterial universal BSF8/20 and BSR1451/209. The sequence of the cloned $16 \mathrm{~S}$ rDNA fragments was compared to data of Genbank using basic local alignment search tool (Shanghai Sangon Biological Engineering Technology and Services Co., Ltd.).

\section{RESULTS AND DISCUSSION}

Isolation and identification of bacteria: For the case of L1, oxidase test, catalase test, glucide oxidation test and nitrate deoxidize test shows the positive results, while glucide ferment test, hydrolysis of starch, methyl red test and Voges-proskauer test demonstrates the negative results. For the case of L2, oxidase test, glucide ferment and oxidation and methyl red test are positive, catalase test, hydrolysis of starch, Vogesproskauer test and nitrate deoxidize test are negative. For the case of L3, catalase test, glucide ferment and oxidation, methyl red test are positive, while oxidase test, hydrolysis of starch, voges-proskauer test and nitrate deoxidize are negative. For the case of L4, oxidase test, catalase test, glucide ferment and oxidation and nitrate deoxidize are positive, hydrolysis of starch, methyl red test and voges-proskauer test are negative. The bacterium was identified according to the physiological and biochemical experiments that L1 is Pseudomonas sp., L2 is Kocuria sp., L3 is Arthrobacter sp. and L4 is Bacillus sp.

By using gas chromatography of bacterial fatty acids with the MIDI Sherlock Microbial Identification System, L1-L4's fatty acids are presented in Figs. 5-8. It is found that L1 responds to Pseudomonas sp., L2, to Kocuria sp., L3, to Arthrobacter sp. and L4, to Bacillus sp.

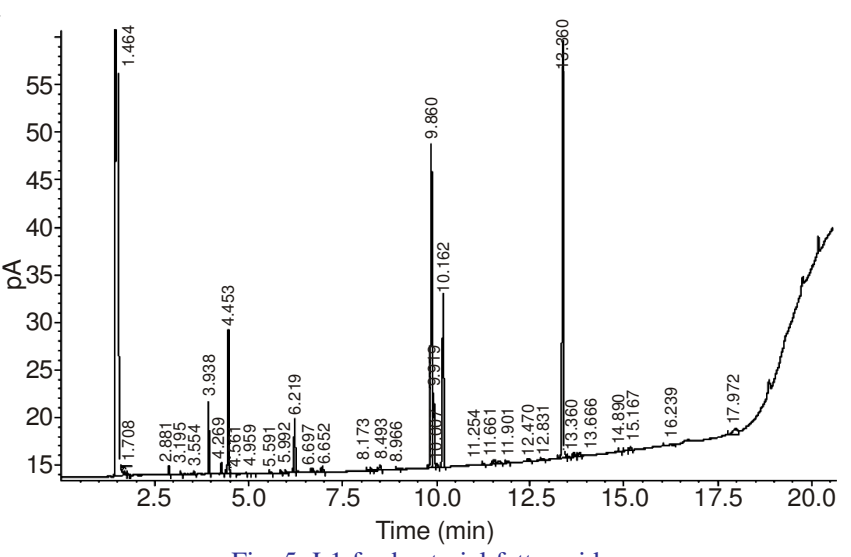

Fig. 5. L1 for bacterial fatty acids

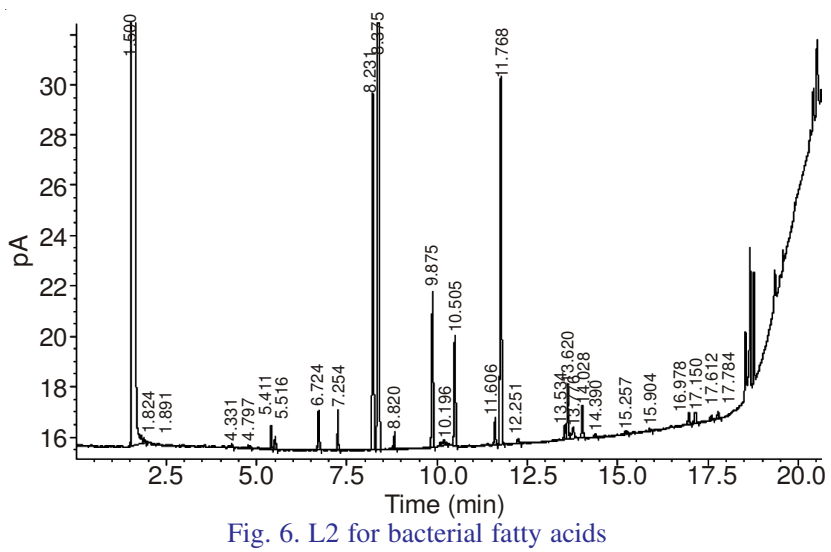




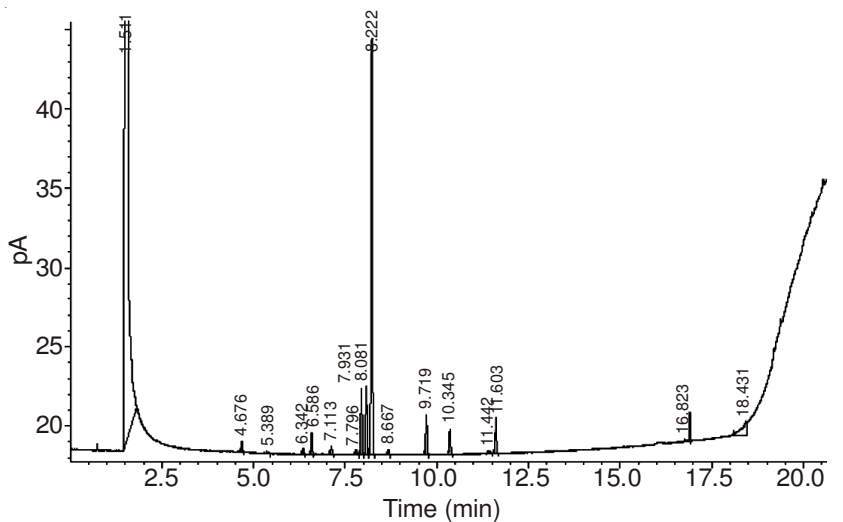

Fig. 7. L3 for bacterial fatty acids

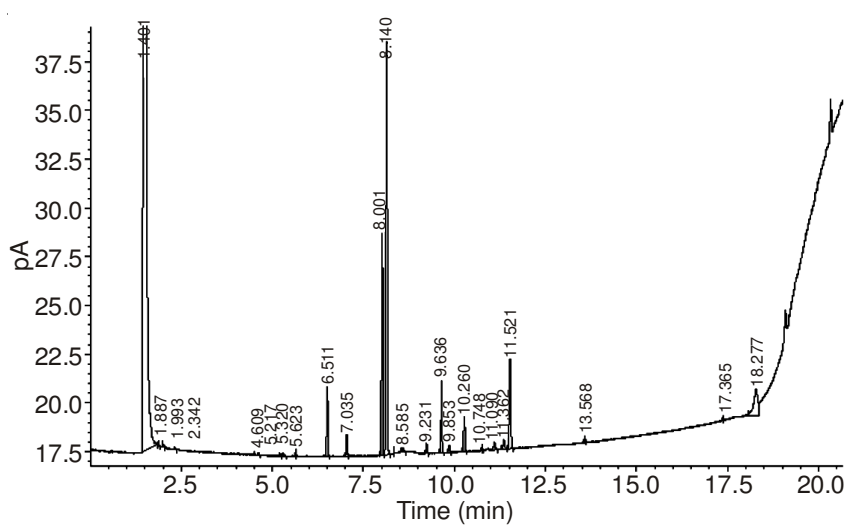

Fig. 8. L4 for bacterial fatty acids

In order to identify strains accurately, molecular analysis was used. By sequencing based on 16S rDNA, the similarity between L1 and Pseudomonas.sp was up to $99 \%$, the similarity between L2 and Kocuria.sp was up to $98 \%$, the similarity between L3 and Arthrobacter.sp was up to $98 \%$ and the similarity between L4 and Bacillus. sp was up to $94 \%$.

By using physiological and biochemical experiments, bacterial fatty acid content and 16S rDNA sequences, the bacterium was confirmed that L1 is Pseudomonas sp., L2 is Kocuria sp., L3 is Arthrobacter sp. and L4 is Bacillus sp..

Effect and dynamic analysis: According to the adsorption-biofilm purification model ${ }^{10}$, the dynamic course of biological treatment for the purification of low volatile organic compounds concentration can be described as:

$$
\begin{gathered}
\eta=\frac{\mathrm{C}_{\text {in }}-\mathrm{C}_{\text {out }}}{\mathrm{C}_{\text {in }}} \times 100 \% \\
\mathrm{C}_{\text {out }}=\mathrm{C}_{\text {in }}-\frac{\mathrm{L}}{\mathrm{GH}_{\mathrm{c}}} \mathrm{C}_{\text {in }}-\mathrm{b} \frac{\lambda \mathrm{C}_{\text {in }}}{1+\lambda \mathrm{C}_{\text {in }}} \cdot \frac{\mathrm{V}}{\mathrm{G}}
\end{gathered}
$$

where $\eta$ is removal efficiency (\%); $\mathrm{C}_{\text {out }}$ is outlet air concentration $\left(\mathrm{mg} / \mathrm{m}^{3}\right) ; \mathrm{C}_{\text {in }}$ is inlet air concentration $\left(\mathrm{mg} / \mathrm{m}^{3}\right) ; \mathrm{G}$ is air flow rate $\left(\mathrm{m}^{3} / \mathrm{h}\right) \mathrm{H}_{\mathrm{c}}$ is Henry constant (-); $\mathrm{L}$ is fluid flow rate $\left(\mathrm{m}^{3} / \mathrm{h}\right)$; b is adsorption constant of biofilm filling $\left(\mathrm{mg} / \mathrm{m}^{3} \cdot \mathrm{h}\right) ; \lambda$ is adsorption coefficient $\left(\mathrm{m}^{3} / \mathrm{mg}\right)$; $\mathrm{V}$ is the volume of packing bed $\left(\mathrm{m}^{3}\right)$.

By eqn. 2, we can obtain adsorption constant of biofilm filling and adsorption coefficient of different substance as Table-1. Compared computed value with experiment value of outlet air concentration from biofilter for different substance,
TABLE-1 b AND $\lambda$ VALUE OF DIFFERENT SUBSTANCE

\begin{tabular}{cccc}
\hline Substance & Benzene & Toluene & Xylene \\
\hline $\mathrm{b}\left(\mathrm{mg} / \mathrm{m}^{3} \mathrm{~h}\right)$ & $4.0554 \times 10^{4}$ & $2.9966 \times 10^{6}$ & $3.5110 \times 10^{5}$ \\
$\lambda\left(\mathrm{m}^{3} / \mathrm{mg}\right)$ & 0.0016 & $3.2273 \times 10^{-5}$ & $2.4361 \times 10^{-4}$ \\
\hline
\end{tabular}

its result can be seen in Fig. 9. From Fig. 9, we can find that the triphenyl outlet concentration model predicted value has great relativity with the actual value. Benzene correlation coefficient $\mathrm{R}=0.9995$, toluene correlation coefficient $\mathrm{R}=0.9996$ and xylene correlation coefficient $\mathrm{R}=0.9996$. Obviously, later period processing of indoor decoration toxic triphenyl gas of the biotrickling filter accords with the adsorption-biofilm theory dynamics model.
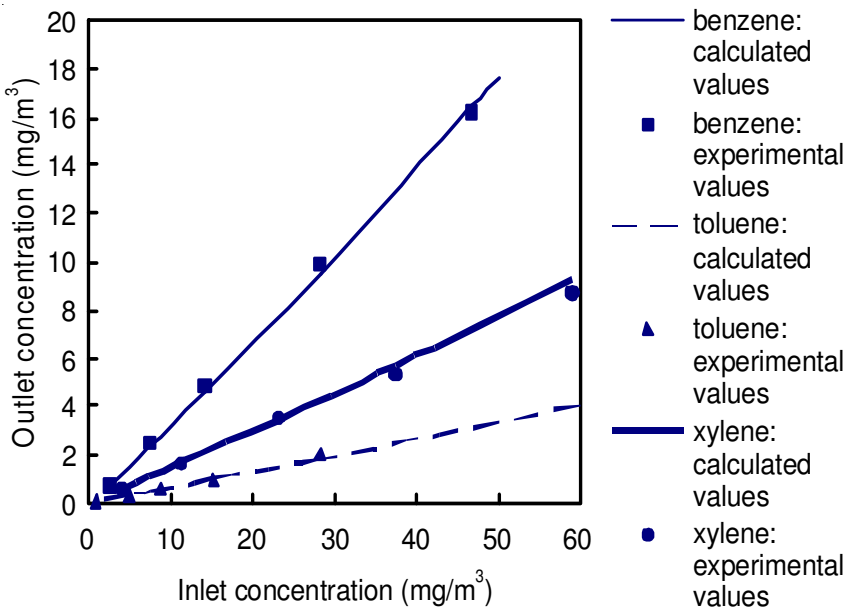

Fig. 9. Simulation and experimental value of VOCs concentration change

\section{Conclusion}

This conclusion is as follows: When flow rate of air stream is $600 \mathrm{~L} / \mathrm{h}$, the liquid flow is $20 \mathrm{~L} / \mathrm{h}$, removal efficiencies under $30{ }^{\circ} \mathrm{C}$ is higher than those under $40{ }^{\circ} \mathrm{C}$ in biotrickling filter. When bake-out temperature is $30^{\circ} \mathrm{C}$, inlet concentration of benzene ranges from $2.254-6.733 \mathrm{mg} / \mathrm{m}^{3}$, purification efficiency is in $65-70 \%$. When inlet concentration of toluene ranges from 0.51 to $28.254 \mathrm{mg} / \mathrm{m}^{3}$, purification efficiency is basically steady in $93 \%$. When inlet concentration of xylene ranges from 4.166 to $59.008 \mathrm{mg} / \mathrm{m}^{3}$, purification efficiency is in $85-90 \%$. When inlet concentration of formaldehyde is smaller than $6.578 \mathrm{mg} / \mathrm{m}^{3}$, the biotrickling filter has been keeping $100 \%$ for formaldehyde purification efficiency all the time. Four highly effective bacteria were optimally screened out from the biotrickling filter. By means of physiological and biochemical experiments, bacterial fatty acid content and $16 \mathrm{~S}$ rDNA Sequences, were identified as Pseudomonas sp. for L1, Kocuria sp. for L2, Arthrobacter sp. for L3 and Bacillus sp. for L4. Based on the adsorption-biofilm purification model, the dynamic course of biological treatment for the low concentration volatile organic triphenyl gas purification indicates that the model predicted value and the actual value correlates greatly. Obviously, it is feasible to use biofilter processing for formaldehyde and volatile organic compounds gas purification. 


\section{ACKNOWLEDGEMENTS}

This research is supported by the Twelfth Five-Year National Technology Key Project (2012BAJ02B05), the SRFDP (20120041120003), the National Nature Science Foundation of China (51308088), the Fundamental Research Funds for the Central Universities (DUT14QY24), the Liaoning Provincial Science and Technology Fund projects, the Dalian Science and Technology Fund projects, and the Dalian Municipal Construction Technology Program.

\section{REFERENCES}

1. L.Y. Wang, A.J. Wang and N.Q. Ren, J. Harbin Inst. Technol., 36, 732 (2004).

2. E.H. Shim, J. Kim, K.S. Cho and H.W. Ryu, Environ. Sci. Technol., 40, 3089 (2006)
3. Y.H. Liu, X. Quan, Y.Z. Zhao, S. Chen and H.M. Zhao, Biochem. Eng. J., 23, 85 (2005)

4. L.P. Wang, S.L. Hua and Y.M. Zhao, J. China Univ. Mining Technol., 35, 641(2006)

5. P.S. Sun, X.W. Yang, R.H. Huang, B. Huang and L.Z. Zhang, J. Chem. Ind. Eng. (China), 49, 316 (1998).

6. R.E. Buchanan and N.E. Gibbons, Bergey's Manual of Determinative Bacteriology, The Williams \& Wilkins Company, Baltimore, edn 8 (1974).

7. Z.B. Wu and W.R. Zhao, Indoor Air Pollution and Purification Technology, Chemical Industry Press, Beijing (2005).

8. M. Sasser, Identification of Bacteria by Gas Chromatography of Cellular Fatty Acids, MIDI Technical Note 101, Microbial ID, Inc., Newark, DE, USA (1990)

9. I.C. Anderson, Appl. Environ. Microbiol., 59, 3525 (1993).

10. P. Sun, R. Huang, B. Huang, X. Yang, Y. Xie and L. Zhang, Acta Sci. Circumstant., 19, 153 (1999). 